\title{
Moralité à six personnages traduite en français moderne par Michel Quereuil et Émilie Goudeau d'après l'édition de Joël Blanchard
}

\section{Paola Cifarelli}

\section{(2) OpenEdition}

Journals

Édition électronique

URL : http://journals.openedition.org/studifrancesi/1098

DOI : 10.4000/studifrancesi. 1098

ISSN : 2421-5856

Éditeur

Rosenberg \& Sellier

\section{Édition imprimée}

Date de publication : 1 novembre 2014

Pagination : $574-575$

ISSN : 0039-2944

\section{Référence électronique}

Paola Cifarelli, « Moralité à six personnages traduite en français moderne par Michel Quereuil et Émilie Goudeau d'après l'édition de Joël Blanchard », Studi Francesi [En ligne], 174 (LVIII | III) | 2014, mis en ligne le 01 novembre 2014, consulté le 18 septembre 2020. URL : http://journals.openedition.org/ studifrancesi/1098; DOI : https://doi.org/10.4000/studifrancesi.1098

Ce document a été généré automatiquement le 18 septembre 2020.

\section{cc) $($ ) $\ominus$}

Studi Francesi è distribuita con Licenza Creative Commons Attribuzione - Non commerciale - Non opere derivate 4.0 Internazionale. 


\title{
Moralité à six personnages traduite en français moderne par Michel Quereuil et Émilie Goudeau d'après l'édition de Joël Blanchard
}

\author{
Paola Cifarelli
}

\section{RÉFÉRENCE}

Moralité à six personnages traduite en français moderne par Michel QUEREUIL et Émilie GOUDEAU d'après l'édition de Joël BLANCHARD, Clermont-Ferrand, Presses Universitaires Blaise Pascal, 2013 («Celis Textes»), pp. 217.

1 La Moralité à six personnages est un texte complexe, étudié en profondeur par Joël Blanchard dans son édition critique parue en 2008, où cet éminent spécialiste proposait de l'attribuer à Henri Baude (Moralité à six personnages BnF fr. 25467, Édition critique par J.B., Genève, Droz, 2008). Le présent volume en constitue la traduction en français moderne, réalisée pour «voir dans ce texte né il y a cinq siècles une pièce vivante, à lire et peut-être à jouer» (p. 7). C'est donc dans le but de permettre à un public plus vaste, qui ne soit pas confiné au cercle restreint des spécialistes, que M.Q. et E.G. ont entrepris cette tâche difficile; en effet cette pièce, si éloignée de notre goût tant pour sa forme dramaturgique que pour la caractérisation et le langage des personnages allégoriques, conserve une certaine actualité pour son argument. Bien que le thème de la Fortune compte parmi les plus typiques de la littérature française du Moyen Âge tardif, les péripéties du protagoniste apprenant à gravir l'échelle sociale sous le guide de Malice restent exemplaires pour leur universalité.

2 Le texte est précédé d'une introduction faisant une large partie au contexte dramatique médiéval, à ses genres et aux différentes formes de moralités. La synopsis (pp. 28-32), indispensable pour s'orienter dans le texte, précède d'une analyse thématique qui suit 
le fil de l'intrigue et d'une étude du jeu et du dispositif scénique (pp. 75-89), dans laquelle les AA. essaient de reconstruire les différents aspects du spectacle; véritables indications pour une mise en scène éventuelle de la pièce, ces observations sur la performance visent à expliquer le fonctionnement des représentations dramaturgiques médiévales.

Pour la traduction en prose, les AA. se sont fondés sur l'édition Blanchard, mais ils ont aussi tenu compte systématiquement - mais toujours critiquement - des observations formulées par Xavier Leroux dans son compte-rendu paru dans la «Revue de Linguistique Romane» (t. 73, 2009, pp. 251-256); ainsi, les corrections au texte de l'édition critique proposées par X.L. ont été accueillies dans sept cas (pp. 96, 101, 104, $108,109,135,141$, vv. 28, 246, 341-345, 476, 525, 1300, 1468), mais il arrive également qu'elles ne soient pas acceptées (ex. v. 75, p. 91); des notes en bas de page rendent compte de toutes les interventions sur le texte de départ. Dans un cas les AA. proposent même une correction de la leçon du manuscrit, plus satisfaisante du point de vue du sens (p. 139, v. 1396 et chemin si long et si brieff: la leçon grieff permet d'éviter la contradiction), ce qui est la preuve que toute traduction, et particulièrement celles de textes anciens, ne peut pas se passer d'un minutieux travail philologique préliminaire, l'activité traduisante étant strictement apparentée à l'herméneutique.

La traduction qui en résulte est très soignée; grâce à l'excellente annotation et au glossaire de l'édition critique, ainsi qu'au travail scrupuleux et compétent des traducteurs qui ne manquent pas de mener des recherches de première main lorsque cela se rend nécessaire, les difficultés nombreuses que présente cette moralité ont pu être surmontées avec précision et élégance; l'on appréciera également l'honnêteté intellectuelle par laquelle les AA. se déclarent parfois impuissants face à quelques passages vraiment incompréhensibles (ex. vv. 76, 1317). Pareillement, dans les notes ils discutent tous les passages controversés donnant lieu à des interprétations divergentes (ex. vv. 67-82) et, conformément au type de public auquel ce travail s'adresse, ils éclaircissent par des informations complémentaires les notes de l'édition critique. L'Index des noms propres et une bibliographie essentielle complètent ce travail, qui conjugue esprit de divulgation et rigueur scientifique. 